\title{
Similarity and cooperation received as determinants of cooperation rendered
}

\author{
H. KAUFMANN $I$ \\ HUNTER COLLEGE
}

$S$ 's perception of high similarity between himself and a fictitious $P$ produced high cooperation and high expectation of cooperation by $P$. A similar P's ostensible competitive behavior produced retaliation, and a dissimilar or control $P$ 's cooperation produced some exploitation. Cooperation by a similar $P$, and competition by dissimilar or control Ps led to no changes in $S$ 's previous strategy.

Non-economic determinants in ostensibly economic interpersonal situations are, in effect, of greater interest to the social psychologist than purely economic ones. It is these non-economic factors which produce the paradoxical situations of economically non-optimal behavior aimed at ensuring a gain (or, sometimes a loss) for another person.

A possible approach takes into account the player's evaluative perception of his opponent. To Illustrate in very general terms, this approach would hypothesize that, say, the degree of similarity which $\mathrm{S}$ perceives to exist between himself and $P$. On the basis of studies showing liking to be positively related to perceived similarity (Byrne, 1961; Byrne \& Nelson, 1964; Kaufmann \& Zener, 1967), greater similarity should lead to more cooperation, as well as to more expected cooperation from P. However, where P disappoints or "betrays" $\mathrm{S}$ by not cooperating, one might expect $S$ to react more competitively against a similar $\mathbf{P}$ of whom much cooperation was expected.

Method

The instrument and procedure used to induce similarity is given in Kaufmann \& Zener (1967), and constituted Task 1. An additional control group received no similarity manipulation, but were simply asked to predict $P^{\prime} s$ response without any previous information.

Task 2 consisted of Pepitone's (1964) strategy game. The game was explained to $S$ in the standard fashion, with some additional emphasis on the importance of "guessing" or "predicting" what the other would do. Ss also played five sample trials with $\mathrm{E}$. Ss were informed that they (and P) would play "several" series of 50 trials each, and would learn about their winnings after each series. After the first $\mathbf{5 0}$ trials, but before the results of the game were given, Ss were asked to estimate P's "red"' (cooperative) choices. The feedback consisting of $S$ 's choices for the first 50 trials constituted the cooperation versus competition manipulation.

Cooperation. Ss were assigned winnings of 82 cents, indicating high cooperation by $\mathrm{P}^{\prime} \mathrm{s} .{ }^{2}$

Competition. Ss were informed that they had won 18 cents, indicating low cooperation by $P$.

A second set of 50 trials was then run, whereupon Ss

\begin{tabular}{|c|c|c|c|c|c|}
\hline Source of Variation & df & SS & MS & $\mathbf{F}$ & $\mathbf{P}$ \\
\hline Treatments & 2 & 105.50 & 52.75 & 9.88 & $<.01$ \\
\hline \multirow[t]{4}{*}{ Within } & 69 & 368.67 & 5.34 & & \\
\hline & \multicolumn{3}{|c|}{ Means } & & \\
\hline & Hi Sim & \multirow{2}{*}{\multicolumn{2}{|c|}{$\begin{array}{c}\text { Lo } \mathrm{Sim} \\
3.69\end{array}$}} & Control & \\
\hline & .76 & & & 1.92 & \\
\hline \multicolumn{2}{|c|}{ t $\mathrm{Hi} \mathrm{Sim}$ - Control } & \multicolumn{2}{|c|}{$=1.74$} & $\mathbf{p}<.05$ & \\
\hline \multicolumn{2}{|c|}{ t Lo Sim - Control } & \multicolumn{2}{|c|}{$=2.67$} & $p<.01$ & \\
\hline
\end{tabular}

were debriefed, adjured to secrecy, and dismissed. Predictions

(1) High similarity produces higher cooperative choices on first 50 trials than low similarity and control.

(2) High similarity produces higher expectation for $\mathrm{P}^{\prime} \mathrm{s}$ cooperation than low similarity and control.

(3) P's simulated non-cooperation reduces S's cooperative choices for second run of 50 trials.

(4) The effect described in (3) is stronger under high similarity than under low similarity and control.

(5) Where $P$ appears to render high cooperation, low similarity and control will "exploit" P more (by making more competitive choices) than high similarity. Results

(1) Reliability of preference scale. S's completion of six items during the experimental session allowed for a consistency check against answers to those same items on the original questionnaire. Ss retained their original preferences quite accurately, with differences rarely reaching $1 / 2$ point.

(2) Success of similarity and manipulation. Mean absolute distances between S's own score on the original questionnaire and that predicted for $P$ were computed (in the case of control Ss, three items were randomly selected from the nine items available for comparison, in order to equalize sources of variance). Results are shown in Table 1. As can be seen, all three conditions differed significantly.

(3) The effects of similarity upon cooperation. The Table 2 Ss' mean red choices in Trial 1

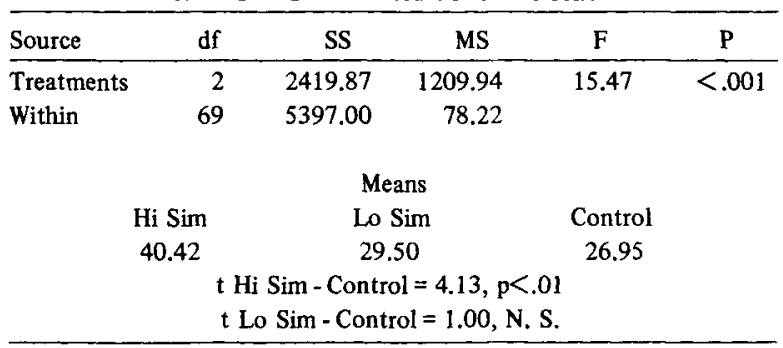


number of red choices in the first 50 trials are a measure of S's cooperation. Table 2 shows that cooperation was significantly greater in the high similar than in the control and the low similar condition, while the latter two did not differ significantly. This supports Prediction 1.

(4) Expectation about P. Table 3 shows means and analysis for Ss' estimates, after 50 trials, about $\mathrm{P}^{\prime} \mathrm{s}$ red choices. Again, more cooperation was expected of 'high similar" than of either of the other two conditions, which did not differ significantly, supporting Prediction 2.

(5) Cooperation after feedback about P. Table 4 shows mean change scores for red choices from first to second run of 50 trials. Prediction 3 was supported only for high-similar Ss. However, Prediction 4, which called precisely for stronger "retaliation" under high similarity, was thus supported.

(6) Prediction No. 5, that high cooperation would produce more exploitation under control and low similarity than under high similarity conditions, was only partially supported. High cooperation controls produced more competitive choices than high cooperation-high similarity. High cooperation-low similarity produced intermediate values, not differing significantly from either of the other two conditions (Table 4).

(7) There was present also a strong interaction effect. Low cooperation produced strong retaliatory effects in the high similarity condition only, while high cooperation further enhanced cooperative choices under high similarity, but produced exploitation in the other two conditions (Table 4).

\section{Discussion}

The results of the experiment corroborate the strong effects which certain interpersonal perceptions have upon social cooperation. Similarity, at least that of the kind induced in this experiment, produced higher cooperation as well as higher expectations of one's partner. Where similarity was high, S apparently took partner's high cooperation as almost his due, and did not increase his subsequent choices substantially (but note that a possible ceiling effect may have been effective here). On the other hand, if $P$ failed to render cooperation, $S$ retaliated vigorously by decreasing his own cooperative choices. The obverse results for the control, and to a

Table 3 Mean red choices expected by $\mathbf{S}$ of $\mathbf{P}$

\begin{tabular}{|c|c|c|c|c|c|}
\hline Source & df & SS & MS & $\mathbf{F}$ & $\mathrm{P}$ \\
\hline Treatments & 2 & 5885.88 & 2942.94 & 35.47 & $<.001$ \\
\hline Within & 64 & 5725.00 & 82.97 & & \\
\hline \multicolumn{6}{|c|}{ Means } \\
\hline \multicolumn{2}{|r|}{ High } & \multicolumn{2}{|c|}{ Low } & Control & \\
\hline \multicolumn{2}{|r|}{45.46} & \multicolumn{2}{|c|}{27.17} & 25.50 & \\
\hline \multicolumn{6}{|c|}{$\begin{array}{l}\text { t Hi Sim - Control }=15.66, p<.0001 \\
\text { t Lo Sim - Control }=0.64, \text { N. S. }\end{array}$} \\
\hline
\end{tabular}

Table 4 Mean change scores of cooperative choices from 1st to 2 nd run of 50 trials

\begin{tabular}{|c|c|c|c|c|c|}
\hline Source & df & SS & MS & F & $\mathbf{P}$ \\
\hline Sim & 2 & 419.20 & 209.60 & 2.56 & $<.10$ \\
\hline Coop & 1 & 89.30 & 89.30 & & \\
\hline Sim X Coop & 2 & 1896.16 & 948.08 & 11.56 & $<.001$ \\
\hline Within & 66 & 5411.34 & 81.99 & & \\
\hline \multicolumn{6}{|c|}{ Means } \\
\hline & & Hi Sim & Lo Sim & Control & \\
\hline Hi Coop & & 1.11 & -3.50 & -6.00 & \\
\hline Lo Coop & & -15.61 & +.25 & +.25 & \\
\hline
\end{tabular}

lesser degree, for the low similarity condition, indicate exploitation of initially cooperative Ps. Apparently, Ss tended to perceive the cooperation tended by a non-similar $P$ to entail no obligation to repay him for favors received.

One aspect of the present study makes the results somewhat less than completely satisfactory. The very effectiveness of the similarity manipulation, and the strong effects of P's behavior on the first 50 trials upon S's responses in the 2nd set of 50 trials, raise at least some doubt that the experimental manipulation may have succeeded not only in establishing high or low perceived similarity, but also to convey covert instructions both about how $S$ was to treat $P$, and what treatment he might in turn expect. In other words, social desirabllity, carefully controlled in the experimental manipulation, may have crept in through the back door. Further, if the experimental results are at least in part due to subjective norms as to how a "similar" vs a "dissimilar" person ought to be treated, and how he in turn ought to behave, these norms might themselves vary as a function of ethnocentrism, hostility, etc.

\section{References}

BYRNE, D. Interpersonal attraction and attitude similarity. J. abnorm. soc. Psychol, 1951, 62, 713-715.

BYRNE, D., \& NELSON, D. The effect of topic importance and attitude similarity-dissimilarity on attraction in a multistranger design.Psychon. $S c i, 1965,3,449-450$.

KAUFMANN, H., \& ZENER, L. Perceived similarity and liking as functions of manipulated similarity and subjective social favorability. Psychon. Sci, 1967, 2,

PEPITONE, A. L. Attraction and hostility. New York: Atherton, 1964. Notes

1. This study was conducted while the author held National Science Foundation Research Grant No. 564.

2. Subsequent consideration showed that 82 cents was an impossible figure if $S$ had used any but a highly exploitative strategy, regardless of the degree of P's cooperation. Two considerations, however, prompted the retention of the data obtained in spite of this flaw: (a) They affect only the high cooperation conditions, while the most interesting results are clearly those where $P$ ostensibly exploited $S$. (b) None of the Ss revealed any puzzlement or incredulity when informed of their winnings. They were, in other words, as unaware of the flaw as was $E$. 